\title{
A UTILIZAÇÃO DE SISTEMAS DE INFORMAÇÕES GEOGRÁFICAS NA ANÁLISE DA TEMPERATURA DA SUPERFÍCIE EM AMBIENTES ANTROPIZADOS
}

\author{
João Cândido André da Silva Neto ${ }^{1}$
}

\section{Natacha Cíntia Regina Aleixo²}

RESUMO: A temperatura da superfície subsidia a compreensão da estrutura térmica urbana e rural conforme os diferentes padrões de uso e ocupação do solo. A partir disso o objetivo deste trabalho é analisar a temperatura da superfície como um importante produto gerado por Sistemas de Informações Geográficas (SIGS) que possibilita a compreensão da mudança no uso do solo e da vulnerabilidade socioambiental. Primeiramente, foram analisados diversos estudos relacionados à climatologia geográfica e geoprocessamento, que utilizaram a carta termal em diferentes recortes geográficos. Além disso, foram coletadas e tratadas as imagens da banda 6 do software Landsat 7 em diferentes estações do ano para a cidade de Ribeirão Preto/SP. As imagens foram tratadas no software Idrisi Andes, no intuito de compreender as áreas com alta temperatura da superfície ao longo do ano. Os resultados demonstraram que durante as estações ocorrem áreas não estacionarias de calor na cidade, no entanto, algumas áreas da região Norte e Centro-Sul da cidade coincidiram no aumento da temperatura nas quatro estações do ano. Dessa forma, a temperatura da superfície demonstrou ser um importante indicador das condições de vulnerabilidade socioambiental na área urbana.

\footnotetext{
${ }^{1}$ Doutor em Geografia, Professor Adjunto da Universidade do Estado do Amazonas.

${ }^{2}$ Doutora em Geografia, Professora Adjunto da Universidade do Estado do Amazonas.
} 
Conclui-se, que esse produto oriundo da integração entre Sensoriamento Remoto e SIG pode contribuir com diferentes tipos de estudos geográficos e implantação de medidas de planejamento e políticas públicas que objetivem uma melhor qualidade de vida.

Palavras-chaves: Climatologia geográfica. Sistemas de informações geográficas. Temperatura da superfície.

\section{INTRODUÇÃO}

A utilização de imagens de satélite em ambiente de Sistemas de Informações Geográficas (SIG) têm propiciado o desenvolvimento de diversas análises em recortes multi-temporais e espaciais, dessa maneira, conforme o tipo de canal utilizado desenvolvem-se cartas de uso do solo, arborização, hidrografia, temperatura da superfície, entre outras. A integração de cartas com mesma base espacial possibilita ainda a análise integrada da paisagem geográfica.

As mudanças no uso e ocupação do solo podem propiciar alterações de temperatura, sendo que nas áreas mais densamente antropizadas, com emprego de materiais construtivos como fibrocimento e alumínio, pela maior absorção de energia tendem a apresentam os maiores valores de temperatura da superfície. (AMORIM et al., 2009; SANT'ANNA NETO, 2011).

Diferentes estudos de clima urbano e geoprocessamento no Brasil analisaram a temperatura da superfície em áreas urbanas e constataram que a carta da temperatura da superfície é um importante indicador das mudanças no uso do solo e da qualidade ambiental urbana. (AMORIM et al., 2009; BARROS, 2013; LIMA e AMORIM, 2011; MOREIRA, 2011; ORTIZ, 2012)

De acordo com Amorim et al (2009, p. 13) "as imagens de satélite podem ajudar a compreender a distribuição das fontes de calor dentro de uma área urbana que levam à formação da llha de Calor Urbana. A estrutura térmica da área urbana interpretada na imagem tratada do Landsat 7 , traduz a ocupação atual, a densidade de construções e a arborização." 
Além disso, a obtenção dessas informações espaciais por meio da temperatura da superfície possibilita a análise de todos esses fatores conjugados, levando ao entendimento da vulnerabilidade socioambiental urbana.

Neste contexto, o presente artigo tem o objetivo de analisar a temperatura da superfície como um importante produto gerado por sensoriamento remoto e SIG que possibilita a compreensão das mudanças no uso do solo e da vulnerabilidade socioambiental em Ribeirão Preto/SP.

\section{DESENVOLVIMENTO}

O município de Ribeirão Preto localiza-se na região Nordeste do Estado de São Paulo, como se observa no mapa 1. Possui altitude de $518 \mathrm{~m}$ e população de 605.114 , sendo 603.401 a população urbana e 1.713 a rural. (IBGE, 2010).

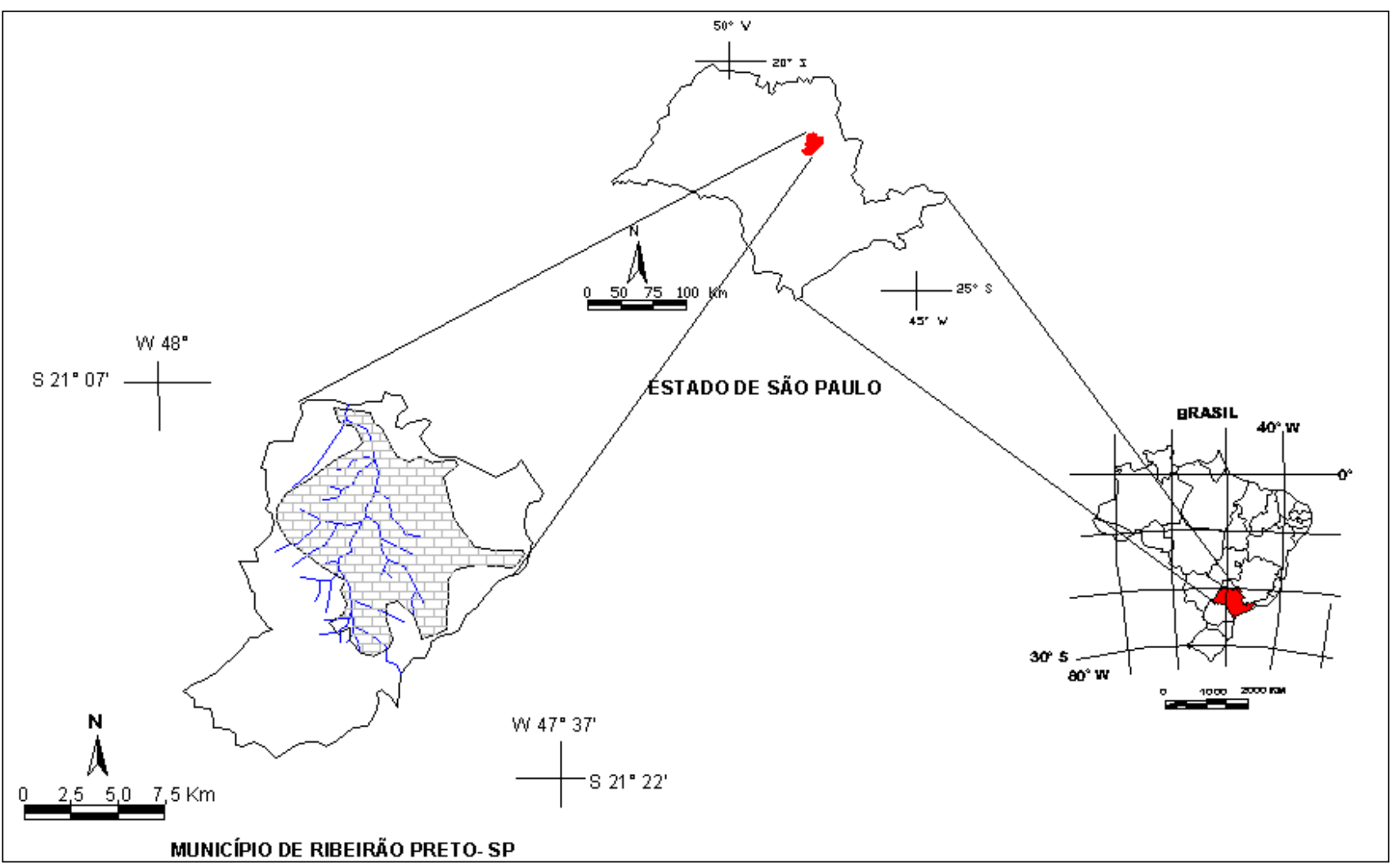

Mapa 1. Localização da área de estudo.

Org.: ALEIXO E SILVA NETO, 2011. 
Segundo Monteiro (1973), a cidade encontra-se na depressão periférica paulista e apresenta uma tipologia climática com dois períodos distintos, primavera-verão com chuvas abundantes e elevada temperatura do ar com predomínio de sistemas equatoriais e tropicais, e outono-inverno seco, com períodos bem marcados de escassez de chuvas controlado por sistemas tropicais e polares.

A temperatura média anual de Ribeirão Preto entre o período de 1978 a 2008 foi de $22,6^{\circ} \mathrm{C}$, atingindo $24,4^{\circ} \mathrm{C}$ nos meses de verão e $20^{\circ} \mathrm{C}$ no inverno. A amplitude térmica entre os valores de temperatura máxima e mínima mensais é maior nos meses de inverno. Ao se observar os valores abaixo e acima da média das temperaturas mínimas e máximas, verificou-se que a quantidade de dias acima de $30^{\circ} \mathrm{C}$ aumentou de 138 nas décadas de 1980 e 1990, para 165 na última década.

Entretanto, os dias com temperatura inferior a $15^{\circ} \mathrm{C}$ têm diminuído a frequência; nas décadas de 1980 e 1990 eram 112 dias, e na última década diminuiu para 89. Assim, o número de dias quentes aumentou cerca de 17\%, enquanto os de dias frios diminuiu em 21\%. Esses dados demonstram o aumento da temperatura na cidade: a média na década de 1980 foi de $22,3^{\circ} \mathrm{C}$ subiu para $22,5^{\circ} \mathrm{C}$ na década de 1990 e $23,1^{\circ} \mathrm{C}$ em 2000.

Após a decadência da produção cafeeira na década de 1930, ocorreu uma desregrada ocupação urbana, pois, muitos agricultores chegaram à falência com a queda do preço do café e migraram para a cidade em busca de oportunidades de emprego e moradia, atraídos também pelas vantagens da proximidade dos serviços de saúde e educação. Assim, expandiram-se os limites territoriais do espaço urbano de Ribeirão Preto, gerando novos assentamentos que eram muitas vezes desprovidos de infraestrutura básica para os citadinos.

Em toda a região de Ribeirão Preto, o café foi sendo substituído por outros cultivos como a cana-de-açúcar, principalmente depois da instituição do Pró-Alcool na década de 1970 pelo Governo Federal. Dessa maneira, o aumento das agroindústrias no município tornou-o um pilar de atração de migrantes pela oferta de empregos. (ELIAS, 2003; GOMES, 2009).

A produção de cana-de-açúcar e a ocupação desordenada do espaço urbano influenciaram no aumento da urbanização que apresenta índices superiores a 
urbanização no Estado e ao dos municípios pertencentes à Região de Governo, bem como alta densidade demográfica. (SEADE, 2009)

O resultado desse processo foi o estabelecimento de muitos bairros sem infraestrutura adequada, produzidos com materiais construtivos de baixo custo, por outro lado, têm-se bairros com alto padrão construtivo dotados de equipamentos e serviços urbanos de qualidade e também a expansão de condomínios fechados. (GOMES, 2009).

Portanto, verifica-se no município a produção desordenada do espaço urbano, com a expansão da área urbanizada, em um processo gerador de desigualdades socioambientais e segregação socioespacial.

Dessa maneira, a compreensão da temperatura da superfície nos auxilia no entendimento dos feedbacks negativos da desordenada produção do uso e ocupação do solo neste recorte espacial.

\subsection{PROCEDIMENTO METODOLÓGICO}

Identificou-se a relação com o uso do solo pela espacialização da temperatura da superfície, por meio da utilização do tratamento da banda 6 do Landsat 7, caracterizando a propriedade térmica dos materiais construtivos, o padrão de uso do solo, a distribuição da vegetação e corpos hídricos.

Para avaliação da temperatura da superfície foram utilizadas imagens do canal infravermelho termal (banda 6) do satélite Landsat-7, com resolução espacial de 60 metros, para Ribeirão Preto.

As imagens selecionadas compreenderam dias representativos no período do verão (05/01/2002), inverno (02/09/2002), primavera (20/10/2002) e outono (27/04/2002), que foram escolhidas pela disponibilidade e pela dinâmica dos sistemas atmosféricos no dia da tomada das imagens (sistemas atmosféricos estáveis, sem chuvas) possibilitando a compreensão do envoltório térmico urbano ${ }^{3}$.

\footnotetext{
${ }^{3}$ No dia $5 / 01 / 2002$, a temperatura média do ar na cidade de Ribeirão Preto, foi de $25,3^{\circ} \mathrm{C}$, com máxima de $32,6^{\circ} \mathrm{C}$ e mínima de $19,9^{\circ} \mathrm{C}$; não ocorreu precipitação pluvial e a umidade relativa diária foi de $71,2 \%$. No dia 02/09/2002, também não ocorreu precipitação pluvial na cidade, a temperatura do ar mínima foi de $7,6^{\circ} \mathrm{C}$ e a máxima de $19,8^{\circ} \mathrm{C}$, a umidade relativa diária foi de $69,4 \%$, característica da atuação dos sistemas polares. No dia $20 / 10 / 2002$ a temperatura máxima foi $34,4^{\circ} \mathrm{C}$ e a mínima de $21^{\circ} \mathrm{C}$ não ocorreu precipitação pluvial e
} 
As imagens foram processadas no software IDRISI, que permite a execução de equações para converte a imagem em radiação espectral $\left(L_{\lambda}\right)$ :

$$
L_{\lambda}=\left(\left(L M A X_{\lambda}-L M I N_{\lambda}\right) /(Q C A L M A X-Q C A L M I N)\right) *(Q C A L-Q C A L M I N)+\text { LMIN }_{\lambda}
$$

Sendo:

QCAL= valor quantizado calibrado em pixel in DN

LMIN $\lambda=A$ radiância espectral que é dimensionado para QCALMIN em watts/(metros quadrados * ${ }^{*}$ ster * $\mu \mathrm{m}$ )

$\operatorname{LMAX} \lambda=A$ radiância espectral que é dimensionado para QCALMAX em watts/(metros quadrados * $\left.{ }^{\text {ster }}{ }^{*} \mu \mathrm{m}\right)$

QCAL = valor mínimo quantizado calibrado em pixel (Correspondente ao LMIN $\lambda$ ) no DN

MIN= 1 (LPGS Produtos)

$=0$ (NLAPS Produtos)

QCALMAX = valor máximo quantizado calibrado em pixel (Correspondente ao LMIN $\boldsymbol{\Lambda}$ ) no $\mathrm{DN}=255$ e posteriormente converter em temperatura em Kelvin (T):

$$
\begin{aligned}
& \mathbf{T}=\frac{\mathbf{K 2}}{\ln \left(\frac{\mathbf{K 1}}{\mathbf{L}_{\lambda}}+\mathbf{1}\right)} \\
& \mathbf{T} \quad=\text { Temperatura efetiva do satélite em Kelvin } \\
& \mathbf{K} 2 \quad=\text { Calibração constante } 2(1282,71) \\
& \mathbf{K} 1 \quad=\text { Calibração constante } 1(666,09) \\
& \mathbf{L} \quad=\text { A radiância espectral em watts } /(\text { metro quadrado * } \text { ster * } \mathbf{m})
\end{aligned}
$$

Posteriormente à execução do procedimento para classificar a imagem em temperatura em Kelvin é necessário converte - lá em graus Celsius. Assim, a imagem Landsat processada e convertida em imagem de temperatura da superfície possibilitou a interpretação e análise das diferenciações de temperatura nas diferentes estações do ano.

a umidade relativa foi de $69,4 \%$. No dia $27 / 04 / 2002$ a temperatura máxima $32,4{ }^{\circ} \mathrm{C}$ e a mínima de $19^{\circ} \mathrm{C}$, não ocorreu precipitação pluvial e a umidade relativa diária foi de $60,5 \%$. 


\subsection{ESTRUTURA E FUNÇÕES DE PROCESSAMENTO DOS SIGS: INTERAÇÕES COM A TEMPERATURA DA SUPERFÍCIE}

Os Sistemas de Informação Geográfica (SIG) possibilitam a integração, na mesma base de dados, de informações geográficas oriundas de fontes distintas tais como dados cartográficos, dados de censo e de cadastro urbano e rural, imagens de satélite e modelos numéricos de terreno, e oferecem ainda "mecanismos para recuperar, manipular e visualizar estes dados, através de algoritmos de manipulação e análise" (CÂMARA et al. 1996, p. 22).

Destaca-se que o termo Sistemas de Informação Geográfica é utilizado para sistemas que efetivam "o tratamento computacional de dados geográficos e recuperam informações não apenas com base em suas características alfanuméricas, mas também através de sua localização espacial" (DAVIS e CÂMARA, 2001, p.42).

Desse modo, os SIG's permitem a inter-relação de dados a partir do fundamento comum da localização geográfica, cujo princípio básico é que todo dado inserido na interface de um SIG, deve estar georreferenciados, ou seja, tem uma localização na superfície terrestre baseado em projeções cartográficas (CÂMARA e MONTEIRO, 2001).

Segundo Fitz (2008) os componentes constituintes para funcionamento de SIGs que é composta por:

Hardware: é a plataforma computacional;

Software: os programas, módulos e programas vinculados;

Dados: pode ser definido como as informações resultantes de uma investigação, normalmente são estruturadas em Planos de Informações (P.I).

Usuário: Profissional que manuseia o software.

Davis e Câmara (2001) apresentam uma visão mais abrangente, para indicar a estrutura geral de um SIG (Figura 1):

$>$ Interface com usuário;

$>$ Entrada e integração de dados;

> Funções de consulta e análise espacial;

$>$ Visualização e plotagem; 
Armazenamento e recuperação de dados (organizados sob a forma de um banco de dados geográficos).

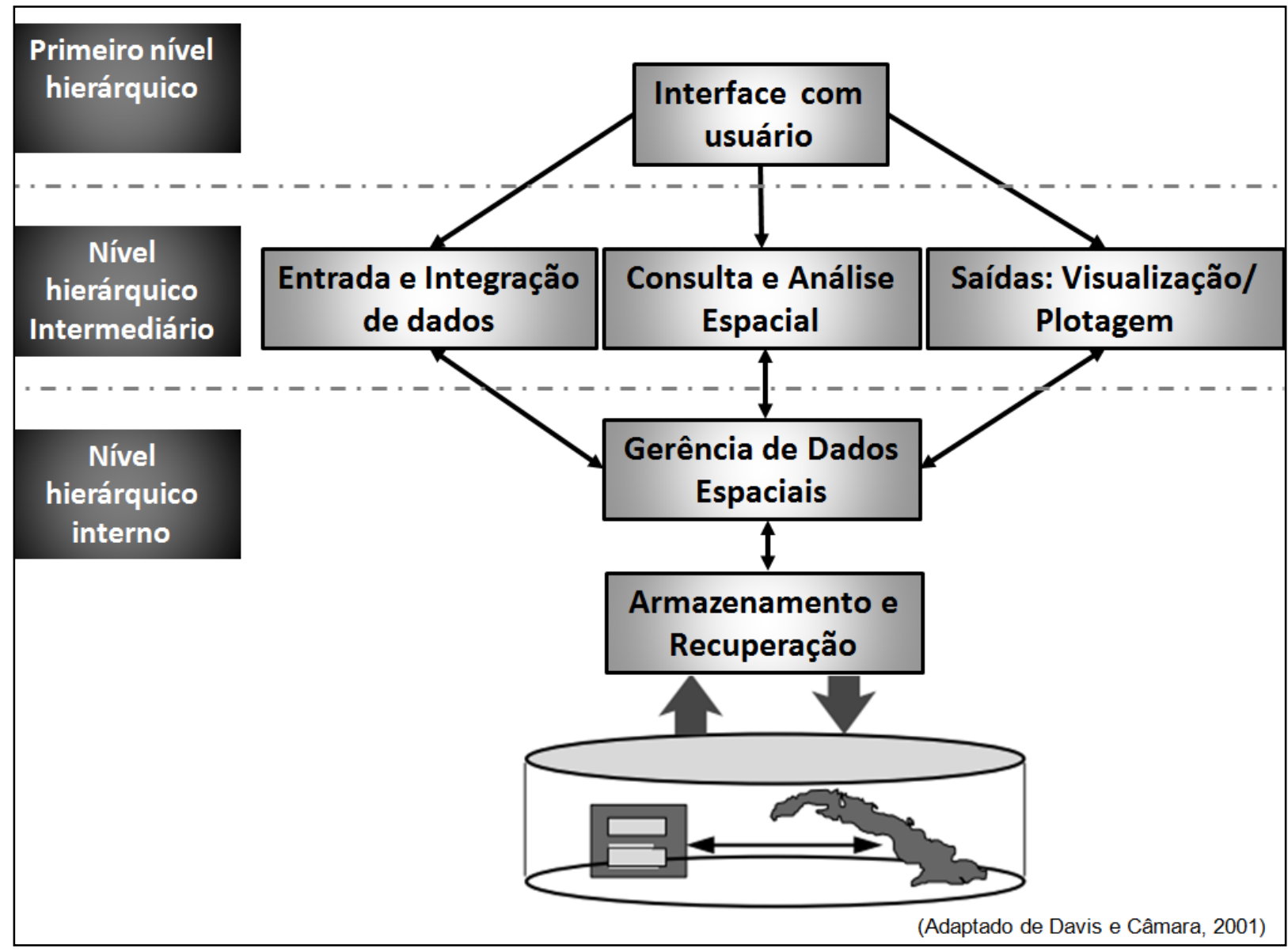

Figura 1. Estrutura geral de SIG. Org.: Silva Neto (2012)

Observa-se que a interface com usuário definirá como o sistema será operado e controlado, portanto, a partir dos objetivos definidos pelo usuário, serão obtidos resultados no SIG, essa interface corresponde ao primeiro nível na hierarquia do SIG.

As entradas e integrações de dados, as funções de consulta e análise espacial, visualização e saídas como plotagens, são destacadas como um nível intermediário do SIG, que correspondem aos mecanismos de processamentos de dados espaciais. 
O sistema de gerência de bancos dados permite que os dados geográficos e seus atributos sejam armazenados e recuperados, em um nível mais interno do sistema, que corresponderia ao hardware utilizado pelo usuário.

Konecny (2003) destaca uma distinção importante na estrutura dos SIGs, enfatizando que num sentido restrito corresponderia ao nível hierárquico interno do SIG, e num sentido amplo, corresponderia ao primeiro e ao nível hierárquico intermediário.

A geographic information system (GIS), in a narrow definition, is a computer system for the input, manipulation, storage and output of digital spatial data. In a more broad definition it is a digital system for the acquisition, management, analysis and visualization of spatial data for the purposes of planning, administering and monitoring the natural and socialeconomic environment. It represents a digital model of geography in its widest sense ${ }^{4}$ (KONECNY, 2003 p.183).

Lang \& Blaschke (2009) enfatizam que o auxílio dos SIGs, permite "explicar e visualizar relações espaciais", possibilitando ainda representar e apresentar essas relações em formato de mapas, além de desenvolver cenários espaciais e avaliar as intervenções humanas inseridas em paisagens naturais.

Segundo Câmara (1993) a característica fundamental de um sistema de geoprocessamento é sua faculdade de armazenar, recuperar e analisar mapas num ambiente computacional. No ambiente de SIG o mapa pode ser considerado uma representação gráfica de fenômenos geográficos, geralmente em uma superfície plana.

Nesse sentido, Fitz (2008) considerou que é possível interpretar que as funções de um SIG estão vinculadas à própria estrutura do sistema, a qual se relaciona com os imperativos do usuário.

Observa-se ainda que as principais funções de processamentos de dados geográficos como as entradas e integrações de dados, as funções de consulta e análise

\footnotetext{
${ }^{4}$ Tradução nossa: "Um Sistema de Informação Geográfica (SIG), em uma definição mais restrita, é um sistema de computador para a entrada, manipulação, armazenamento e saída de dados digitais espaciais. Em uma definição mais ampla é um sistema digital de aquisição, gestão, análise e visualização de dados espaciais para fins de planejamento, gestão e monitoramento do ambiente natural e socioeconômico. Ele representa um modelo digital da Geografia em seu sentido mais amplo".
} 
espacial, visualização e saídas estão situados no nível hierárquico intermediário da estrutura do SIG.

Para Fitz (2008) as principais funções do SIG são a aquisição e edição de dados (entrada de dados, input), gerenciamento do banco de dados (manuseio e escolha de variáveis), análise geográfica de dados (correlações e sobreposição de variáveis) e representação de dados (mapas, gráficos, tabelas, relatórios).

É importantes ressaltar que os SIGs abrangem diferentes tipos de dados geográficos, como imagens de satélites, modelos numéricos de terreno, vetores, raster. Desse modo, possibilitam a integração em uma única base de dados dos diferentes tipos de dados geográficos.

Uma característica básica e geral de um SIG é a sua capacidade de tratar as relações espaciais entre objetos geográficos. Denota-se por topologia a estrutura de relacionamentos espaciais (vizinhas, proximidade, pertinência) que podem se estabelecer entre objetos geográficos. (CÂMARA, 1993, p. 15).

O autor considera que o armazenamento da topologia de um mapa é uma das características básicas que diferenciam os SIG's de outros sistemas computacionais, outra diferença marcante é a capacidade de tratar as diversas projeções cartográficas.

Os SIGs possibilitam as aplicações de funções como a análise geográfica, que pode ser definida como a combinação de informações temáticas, que consistem em funções como a superposição, ponderação, medidas e consulta de banco de dados.

É cada vez mais comum a utilização das imagens orbitais nos estudos relacionados à análise ambiental, de modo como o processamento dessas imagens resultam em subsídios para análise de temperatura de superfície, uso do solo entre outros parâmetros importantes na configuração ambiental de uma determinada região, município, cidade, etc.

As alterações nos tipos de uso do solo pode, muitas vezes, acarretar mudanças de temperatura desencadeando uma série de variações no tocante da própria estrutura dos solos e, por sua vez, no ambiente modificado, observando ainda a possibilidade de associar as áreas de temperaturas mais elevadas com as áreas mais antropizadas.

Além disso, a influência de diferentes tipos de materiais utilizados em coberturas residenciais é apontada na literatura científica como uma das variáveis no acréscimo de 
calor no ambiente urbano. A associação do desconforto térmico com os materiais construtivos também indica a desordenada e precária apropriação do espaço pelos agentes sociais com menor poder aquisitivo.

$\mathrm{Na}$ Tabela 4, de acordo com Ferreira e Prado (2003), os materiais metálicos atingem temperaturas superficiais altas, como o fibrocimento, aço galvanizado sem pintura e alumínio sem pintura que apresentaram $10,3^{\circ} \mathrm{C}, 21,1^{\circ} \mathrm{C}$ e $32,6^{\circ} \mathrm{C}$ na diferença entre a temperatura do ar e do material.

Por isso, ao se pensar no tema do conforto e desconforto térmico e sua influência na qualidade de vida urbana, deve-se considerar a temperatura da superfície como resultado da forma urbana e da produção desigual do espaço, uma vez que a exposição às altas temperaturas da superfície decorrentes dos materiais empregados, assim como a vulnerabilidade, ocorre com agentes sociais mais desprovidos economicamente.

Nas áreas mais vulneráveis dos municípios em todo o país, muitas moradias são construídas com materiais como o fibrocimento e o alumínio, que podem aumentar o desconforto térmico dos citadinos, pelas intensas readaptações fisiológicas do metabolismo humano ás altas amplitudes térmicas vivenciadas nos diferentes períodos do dia. 
Tabela 1. Temperatura superficial e do ar por condições climáticas determinadas pela ASTM (1980-1998).

\begin{tabular}{|c|c|c|c|c|c|}
\hline \multicolumn{2}{|c|}{ Material } & $\begin{array}{c}\text { Albedo } \\
\text { Envelhecido }\end{array}$ & $\begin{array}{l}\text { Emissividade } \\
\text { do Material }\end{array}$ & $\begin{array}{c}\text { Temp. } \\
\text { Superficial } \\
\left({ }^{\circ} \mathrm{C}\right)\end{array}$ & $\begin{array}{c}\text { Diferença de } \\
\text { temperatura } \\
\text { entre o ar e o } \\
\text { material }\left({ }^{\circ} \mathrm{C}\right)\end{array}$ \\
\hline \multicolumn{2}{|c|}{ Cerâmica Vermelha } & 0,53 & 0,9 & 36,8 & $-0,1$ \\
\hline \multicolumn{2}{|c|}{ Cerâmica Branca } & 0,54 & 0,9 & 36,2 & $-0,6$ \\
\hline \multicolumn{2}{|l|}{ Fibrocimento } & 0,34 & 0,9 & 47,1 & 10,3 \\
\hline \multirow{10}{*}{ Alumínio } & Sem pintura & 0,57 & 0,05 & 69,4 & 32,6 \\
\hline & Marfim & 0,47 & 0,9 & 40,1 & 3,2 \\
\hline & Amarelo & 0,45 & 0,9 & 41,2 & 4,3 \\
\hline & Bege & 0,45 & 0,9 & 41,2 & 4,3 \\
\hline & Azul Claro & 0,42 & 0,9 & 42,8 & 6,0 \\
\hline & Cinza Platina & 0,41 & 0,9 & 43,3 & 6,5 \\
\hline & Vermelha & 0,38 & 0,9 & 45,0 & 8,1 \\
\hline & Azul Santiago & 0,31 & 0,9 & 48,7 & 11,9 \\
\hline & Verde Imperial & 0,28 & 0,9 & 50,3 & 13,5 \\
\hline & $\begin{array}{l}\text { Cerâmica } \\
\text { Asteca }\end{array}$ & 0,26 & 0,9 & 51,4 & 14,5 \\
\hline \multirow{9}{*}{$\begin{array}{c}\text { Aço } \\
\text { Galvanizado }\end{array}$} & Sem pintura & 0,57 & 0,25 & 57,9 & 21,1 \\
\hline & Branco & 0,49 & 0,9 & 39,2 & 2,3 \\
\hline & Amarelo & 0,37 & 0,9 & 45,5 & 8,7 \\
\hline & Cinza Claro & 0,33 & 0,9 & 47,6 & 10,8 \\
\hline & Vermelho & 0,32 & 0,9 & 48,2 & 11,3 \\
\hline & Azul Escuro & 0,28 & 0,9 & 50,3 & 13,5 \\
\hline & Cinza Escuro & 0,27 & 0,9 & 50,8 & 14,0 \\
\hline & Verde & 0,21 & 0,9 & 54,0 & 17,1 \\
\hline & Cerâmica & 0,20 & 0,9 & 54,5 & 17,7 \\
\hline Metal (Al + Z) & Sem pintura & 0,54 & 0,25 & 60,1 & 23,2 \\
\hline \multirow{8}{*}{$\begin{array}{l}\text { Cimento } \\
\text { Colorido }\end{array}$} & Cinza Escuro & 0,26 & 0,9 & 50,8 & 14,0 \\
\hline & $\begin{array}{l}\text { Cinza Escuro } \\
\text { com Resina }\end{array}$ & 0,13 & 0,9 & 58,1 & 21,3 \\
\hline & Cinza Claro & 0,49 & 0,9 & 49,8 & 12,9 \\
\hline & $\begin{array}{l}\text { Cinza Claro } \\
\text { com Resina }\end{array}$ & 0,27 & 0,9 & 50,8 & 14,0 \\
\hline & Vermelho & 0,37 & 0,9 & 53,5 & 16,6 \\
\hline & $\begin{array}{l}\text { Vermelho } \\
\text { com Resina }\end{array}$ & 0,28 & 0,9 & 50,3 & 13,5 \\
\hline & Ocre & 0,33 & 0,9 & 50,8 & 14,0 \\
\hline & $\begin{array}{l}\text { Ocre com } \\
\text { Resina }\end{array}$ & 0,23 & 0,9 & 52,9 & 16,1 \\
\hline \multirow{4}{*}{$\begin{array}{l}\text { Metal Termo - } \\
\text { Acústico }\end{array}$} & Branca & 0,32 & 0,66 & 46,1 & 9,3 \\
\hline & Alumínio & 0,28 & 0,25 & 59,4 & 22,5 \\
\hline & Verde & 0,27 & 0,4 & 56,3 & 19,4 \\
\hline & Cerâmica & 0,43 & 0,66 & 50,2 & 13,4 \\
\hline
\end{tabular}

Fonte: FERREIRA e PRADO, 2003.

A temperatura da superfície pode ser um produto importante para comparar o emprego desses materiais inadequados ao conforto térmico nos diferentes bairros de um 
espaço urbano, demonstrando as diferenças térmicas na cidade. Para Sant'Anna Neto (2011, p. 52) "o resultado desta interação entre a radiação (balanço de energia) e o espaço construído é um dos fatores que determinam o aquecimento da atmosfera urbana".

Dentre as possibilidades de mensuração, na área urbana de Ribeirão Preto, utilizou-se das técnicas de sensoriamento remoto, para compreensão da estrutura térmica.

A partir do tratamento da banda do infravaermelho-termal do satélite Landsat 7 ETM, obtiveram-se imagens da temperatura de superfície da cidade, em dias representativos das quatro estações (primavera, verão, outono, inverno) do ano de 2002. (Figuras 1, 2, 3, 4)
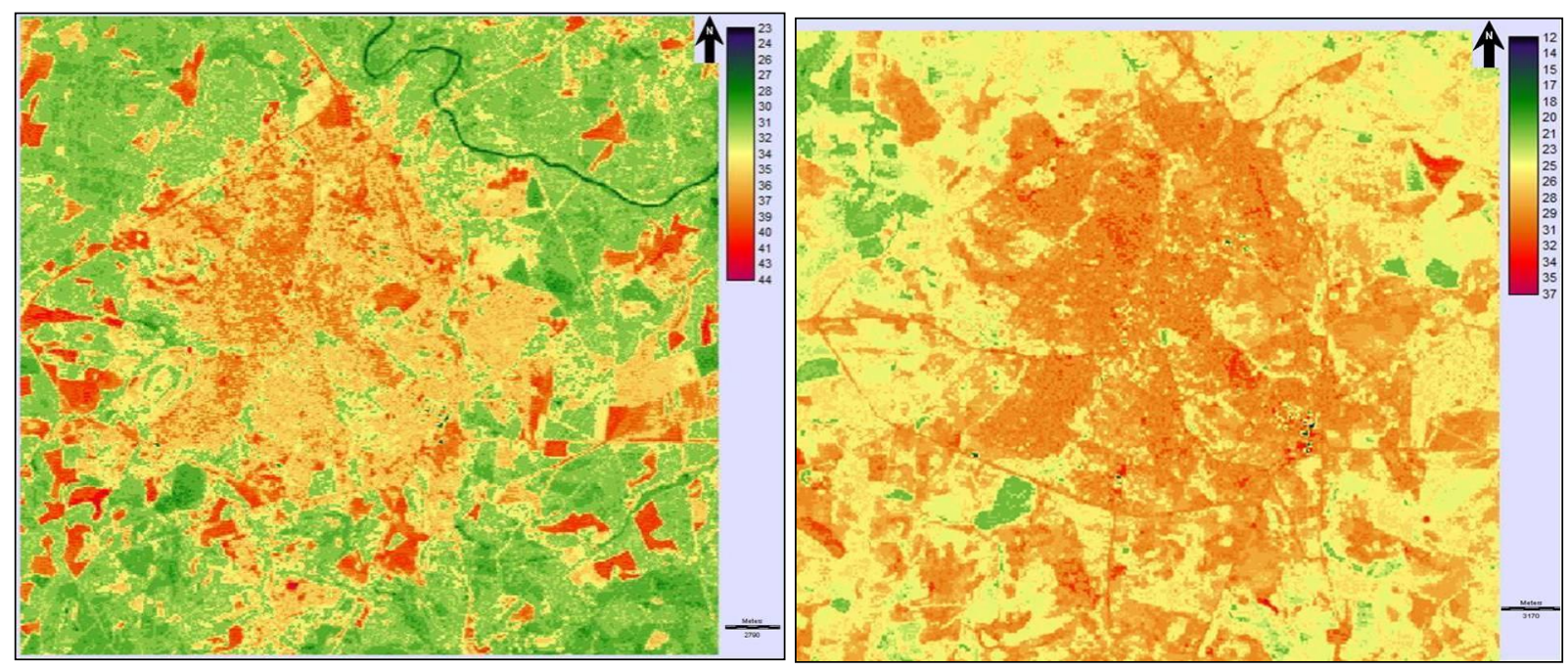

Figuras 1 e 2: Imagens termais da cidade de Ribeirão Preto, recorte da cena 220/75, em dia de verão (05/01/2002) e inverno (02/09/2002) 

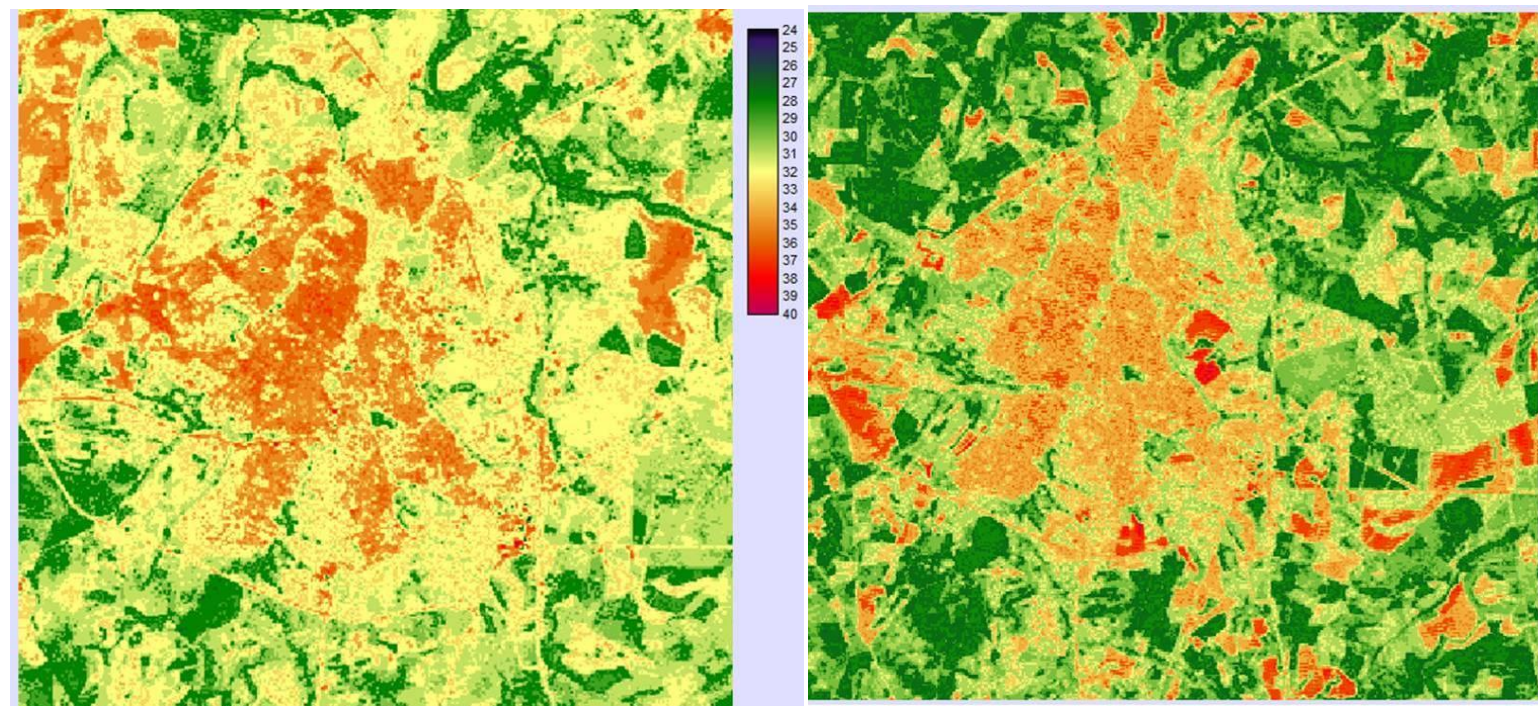

Figuras 3 e 4: Imagens termais da cidade de Ribeirão Preto, recorte da cena 220/75, em dia de primavera (20/10/2002) e outono (27/04/2002)

Verificou-se que durante as estações ocorrem áreas não estácionárias de calor em Ribeirão Preto, no entanto, algumas áreas da região Norte e Centro-Sul da cidade coincidiram no aumento da temperatura nas quatro estações do ano.

Freitas e Lombardo (2007) em um estudo sobre as áreas verdes na cidade de Ribeirão Preto verificaram de forma similar que o Subsetor Norte apresentou as temperaturas mais elevadas e a taxa de ocupação da vegetação arbórea identificada na área foi de apenas $0,76 \%$. As autoras verificaram que a taxa de ocupação arbórea foi mais representativa na área central $(2,25 \%)$ da cidade, que cooperou para que esta área apresentasse temperaturas menores.

A distribuição da temperatura de superfície obtida no tratamento da banda termal, nos dias representativos das quatro estações no ano de 2002 foram diferentes, como pode ser observado na tabela 2 , que se refere às temperaturas da superficie máxima $e$ mínima absolutas. 
Tabela 2. Valores da temperatura de superfície na cidade de Ribeirão Preto/SP.

\begin{tabular}{ccccc}
\hline Temp. Superfície $\left({ }^{\circ} \mathbf{C}\right)$ & primavera & verão & outono & inverno \\
\hline Mínimo & 23,2 & 24,3 & 24,2 & 12,2 \\
Máximo & 43,7 & 43,1 & 40,0 & 37,2 \\
Média & 33,4 & 33,7 & 32,1 & 24,7 \\
Amplitude & 20,5 & 18,9 & 15,8 & 25,0 \\
Desv. Padrão & 14,5 & 13,3 & 11,1 & 17,7 \\
\hline
\end{tabular}

A diferença entre a temperatura de superfície máxima e mínima na primavera foi de $20,5^{\circ} \mathrm{C}$, no verão de $18,9^{\circ} \mathrm{C}$, no outono $15,8^{\circ} \mathrm{C}$ e no inverno de $25,0^{\circ} \mathrm{C}$.

A maior temperatura média foi observada no verão com $33,7^{\circ} \mathrm{C}$ e a menor, no inverno $24,7^{\circ} \mathrm{C}$, coincidindo com a característica climática da cidade, de invernos com predomínio de baixa temperatura e umidade, atuando sistemas polares e tropicais, mas, verão com altas temperaturas e pluviosidade, com predomínio de sistemas equatoriais e tropicais.

Além do inverno apresentar maior amplitude da temperatura, a imagem termal demonstrou o aumento da temperatura no solo rural, nas bordas da cidade, relacionada ao solo exposto no período da safra pós-colheita da cana-de-açúcar.

No outono, a cobertura vegetal na borda da cidade é maior, minimizando o efeito da temperatura de superfície. Por isso, a temperatura de superfície e eficaz em pesquisas espaço-temporais que caracterizam o uso e ocupação do solo em area urbana.

A produção do espaço desigual gerou na área Norte da cidade contrastes térmicos prejudiciais a qualidade de vida dos citadinos e demonstrou que os aspectos relacionados à infraestrutura das moradias bem como dos equipamentos urbanos devem ser melhorados nessas áreas. Portanto, o conhecimento da temperatura da superfície serviu como alicerce para esse diagnóstico.

Portanto, a temperatura da superfície é um importante indicador para se produzir políticas mais igualitárias a qualidade de vida dos citadinos, distanciando-se da lógica de segregação-desigualdade e direcionando a melhoria e organização equipamentos e infraestruturas socioambientais das áreas. 


\section{CONCLUSÃO}

A utilização de Sistemas de Informações Geográficas em análises ambientais aumentaram de forma considerável, a partir da década de 1990, permitindo a inter-relação analítica entre as diferentes escalas geográficas para identificação das múltiplas facetas vinculadas aos problemas socioambientais.

$\mathrm{O}$ tratamento da imagem infravermelha em diferentes recortes temporais para a mesma localidade espacial permitiu o diagnóstico dos diferentes tipos de uso e ocupação do solo urbano, relacionando-os diretamente aos materiais empregados no padrão construtivo.

Dessa maneira, pode-se identificar as diferentes vulnerabilidades relacionadas à diminuição da qualidade de vida da população, principalmente na área Norte da cidade de Ribeirão Preto, pelas acentuadas diferenças térmicas que potencializam o desconforto térmico e a readaptação constante do metabolismo humano.

No Brasil, a relação do homem com a moradia é fraternal; por isso, deveriam ser subsidiadas as compras de materiais adequados ao clima tropical, com isolamento térmico e ventilação adequada.

Além disso, a carta da temperatura da superfície oferece importantes dados para ser utilizada como um indicador de planejamento urbano e subsidia a formulação de políticas públicas infraestruturais e de saúde ambiental visando à qualidade de vida dos citadinos.

\section{REFERÊNCIAS}

AMORIM, M.C.C.T. Características das ilhas de calor em cidades de porte médio: exemplos de Presidente Prudente (Brasil) e Rennes (França). Revista Confins, n.7, 2009, p. 13-16.

BARROS, H.R. Zoneamento climático urbano da cidade do Recife: Uma contribuição ao planejamento urbano. In.: Revista GEOUSP, São Paulo, n.33, p.186-197, 2013. 
CÂMARA, G. Anatomia de Sistemas de Informações Geográficas: visão atual e perspectivas de evolução. In: ASSAD, E. D. e SANO,E. E. Sistemas de Informações Geográficas: Aplicações na Agricultura. 1a ed. Brasília - Embrapa - CPAC, 1993. p. 15-37.

CÂMARA et al. Anatomia de Sistemas de Informação Geográfica. São José dos Campos: Divisão de Processamento de Imagens: Instituto Nacional de Pesquisas Espaciais. 1996.

CÂMARA, G. e MONTEIRO, A. M. V. Cap. 2. Conceitos básicos em ciência da geoinformação. In: CÂMARA, G.; DAVIS, C. e MONTEIRO, A. M. V. Introdução à Ciência da Geoinformação. São José dos Campos. INPE-10506-RPQ/249, 2001. 7- 41 p.

DAVIS, C. e CÂMARA, G., Arquitetura De Sistemas De Informação Geográfica. In: Gilberto Câmara, Clodoveu Davis e Antônio Miguel Vieira Monteiro, Introdução à Ciência da Geoinformação. São José dos Campos. INPE-10506-RPQ/249, 2001. $42-76$ p.

FERREIRA, F. L.; PRADO, R. T. A.. Medição do albedo e análise da sua influência na temperatura superficial dos materiais utilizados em coberturas de edifícios no Brasil. In: Boletim Técnico da Escola Politécnica da USP. São Paulo, EPUSP, 2003.

FITZ, P. R. Geoprocessamento sem complicação. São Paulo: Oficina de Textos, 2008.

FREITAS; LOMBARDO, M.A. O uso de imagem termal para identificar o fenômeno de ilha de calor na área urbana da cidade de Ribeirão Preto-SP/Brasil. Anais Pluris, 2006. Porto, Portugal, p.1-10.

GOMES, M. A. S. Parques urbanos de Ribeirão Preto-SP: na produção do espaço, o espetáculo da natureza. 2009, 260f. Tese de doutorado em Geografia. Universidade de Campinas, 2009.

INSTITUTO BRASILEIRO DE GEOGRAFIA E ESTATÍSTICA (IBGE). Censo Demográfico do Brasil - Resultado do Universo. Rio de Janeiro: IBGE. 2010.

INSTITUTO NACIONAL DE PESQUISAS ESPACIAIS (INPE). Banco de imagens de satélite. Disponível em: www.inpe.gov.br.Consultado em: 28/04/2011.

KONECNY, Gottfried. Geoinformation: Remote sensing, photogrammetry and geographic information systems. London and New York, Taylor \& Francis Group, 2003.

LANG, Stefan; BLASCHKE, Thomas. Análise da paisagem com SIG, tradução Hermann Kux. São Paulo: Oficina de texto. 2009.

LIMA, V.; AMORIM, M.C.C.T. A utilização de informações de temperatura da superfície, do NDVI e de temperatura do ar na análise de qualidade ambiental 
urbana. Anais XV Simpósio Brasileiro de Sensoriamento Remoto - SBSR, Curitiba, PR, Brasil, 30 de abril a 05 de maio de 2011, INPE p.1028-1035.

MONTEIRO, C.A. de F. Teoria e Clima Urbano. São Paulo: Universidade de São Paulo, Instituto de Geografia, 1976.

MONTEIRO, C. A de F. A dinâmica climática e as chuvas no estado de São Paulo: estudo geográfico sob a forma de Atlas. USP/IGEOP. São Paulo, 1973.

MOREIRA, E.B.M. Identificação do fenômeno ilhas de calor na área urbana do Recife-PE. Através do canal infravermelho termal do satélite Landsat 5. Anais XV Simpósio Brasileiro de Sensoriamento Remoto-SBSR, Curitiba, PR, Brasil, 30 de abril a 05 de maio de 2011, INPE, p.0678-0775.

ORTIZ, G. O clima urbano de Cândido Mota: Análise do perfil térmico e higrométrico em episódios de verão. Dissertação de Mestrado em Geografia. Universidade Estadual Paulista, Presidente Prudente, 2012.

SANT'ANNA NETO, J.L. O clima urbano como construção social: da vulnerabilidade polissêmica das cidades enfermas ao sofisma utópico das cidades saudáveis. Revista Brasileira de Climatologia, ano 7, v. 8, p. 45-60, 2011.

SEADE. Informações demográficas por município e região administrativa. Disponível em: www.seade.sp.gov.br. Consultado em: 20/11/2009. 